\title{
Group art therapy as an adjunctive treatment for people with schizophrenia: multicentre pragmatic randomised trial
}

\begin{abstract}
Mike $\mathrm{J}$ Crawford professor in mental health research ${ }^{1}$, Helen Killaspy reader in rehabilitation psychiatry $^{2}$, Thomas R E Barnes professor of clinical psychiatry ${ }^{1}$, Barbara Barrett lecturer in health economics ${ }^{3}$, Sarah Byford reader in health economics ${ }^{3}$, Katie Clayton head of arts therapies ${ }^{4}$, John Dinsmore research associate ${ }^{5}$, Siobhan Floyd research associate ${ }^{6}$, Angela Hoadley research associate $^{2}$, Tony Johnson senior statistician ${ }^{7}$, Eleftheria Kalaitzaki medical statistician ${ }^{8}$, Michael King professor of primary care psychiatry ${ }^{2}$, Baptiste Leurent medical statistician ${ }^{8}$, Anna Maratos head of arts therapies ${ }^{9}$, Francis A O'Neill senior clinical lecturer ${ }^{5}$, David P Osborn senior clinical lecturer $^{2}$, Sue Patterson research associate ${ }^{1}$, Tony Soteriou director of research and development ${ }^{6}$, Peter Tyrer professor of community psychiatry ${ }^{1}$, Diane Waller honorary professor of art psychotherapy $^{1}$, on behalf of the MATISSE project team
\end{abstract}

\footnotetext{
${ }^{1}$ Centre for Mental Health, Department of Medicine, Imperial College London, Claybrook Centre, London W6 8LN, UK; ${ }^{2}$ Unit of Mental Health Sciences, Faculty of Brain Sciences, University College London, London, UK; ${ }^{3}$ Centre for the Economics of Mental Health, Health Service and Population Research Department, King's College London, London UK; ${ }^{4}$ Camden and Islington NHS Foundation Trust, London, UK; ${ }^{5} \mathrm{Centre}$ for Public Health, Queen's University, Belfast, UK; ${ }^{6}$ Avon and Wiltshire Mental Health Partnership NHS Trust, Chippenham, UK; ${ }^{7} \mathrm{MRC}$ Biostatistics Unit, Cambridge, UK, and MRC Clinical Trials Unit London, UK; ${ }^{8} \mathrm{MRC}$ General Practice Research Framework, London, UK; ${ }^{9} \mathrm{Central}$ and North West London NHS Foundation Trust, London, UK
}

\begin{abstract}
Objectives To evaluate the clinical effectiveness of group art therapy for people with schizophrenia and to test whether any benefits exceed those of an active control treatment.

Design Three arm, rater blinded, pragmatic, randomised controlled trial. Setting Secondary care services across 15 sites in the United Kingdom. Participants 417 people aged 18 or over, who had a diagnosis of schizophrenia and provided written informed consent to take part in the study.

Interventions Participants, stratified by site, were randomised to 12 months of weekly group art therapy plus standard care, 12 months of weekly activity groups plus standard care, or standard care alone. Art therapy and activity groups had up to eight members and lasted for 90 minutes. In art therapy, members were given access to a range of art materials and encouraged to use these to express themselves freely. Members of activity groups were offered various activities that did not involve use of art or craft materials and were encouraged to collectively select those they wanted to pursue.
\end{abstract}

Main outcome measures The primary outcomes were global functioning,
measured using the global assessment of functioning scale, and mental
health symptoms, measured using the positive and negative syndrome
scale, 24 months after randomisation. Main secondary outcomes were
levels of group attendance, social functioning, and satisfaction with care
at 12 and 24 months.
Results 417 participants were assigned to either art therapy ( $\mathrm{n}=140)$,
activity groups (n=140), or standard care alone ( $\mathrm{n}=137)$. Primary
outcomes between the three study arms did not differ. The adjusted
mean difference between art therapy and standard care at 24 months
on the global assessment of functioning scale was -0.9 (95\% confidence
interval -3.8 to 2.1), and on the positive and negative syndrome scale
was 0.7 (-3.1 to 4.6). Secondary outcomes did not differ between those
referred to art therapy or those referred to standard care at 12 or 24
months.

Conclusions Referring people with established schizophrenia to group art therapy as delivered in this trial did not improve global functioning, mental health, or other health related outcomes.

Trial registration Current Controlled Trials ISRCTN46150447. 


\section{Introduction}

Schizophrenia is a severe mental disorder that affects as many as 1 in 100 people at some point in their lives. In addition to "positive" symptoms such as hallucinations and delusions, many people also experience varying degrees of loss of energy and motivation, impaired attention, and other so called negative symptoms. ${ }^{1}$ Although treatment with antipsychotic drugs reduces the positive symptoms of schizophrenia and decreases the likelihood of relapse, it has little impact on negative symptoms. ${ }^{2}$ Psychological and social interventions are widely used in combination with drugs in an effort to further improve the health and social outcomes of people with schizophrenia, and several interventions have been shown to be effective. ${ }^{4}$

The possibility that involvement in creative activities can improve health has often been discussed but rarely examined. ${ }^{5}$ It has been argued that for people with severe mental disorders such as schizophrenia, art therapy has advantages over other treatments because the use of art materials can help people to understand themselves better while containing powerful feelings that might otherwise overwhelm them. ${ }^{6}$ Few attempts have been made to examine the effectiveness of group art therapy as an adjunctive treatment for people with schizophrenia, ${ }^{7}$ but the results of a pilot trial suggested that it may help bring about clinically important reductions in negative symptoms of schizophrenia. ${ }^{8}$ Findings of this study, together with those of trials of other creative therapies, have resulted in the inclusion of arts therapies in national treatment guidelines, which recommend that clinicians consider referring all people with schizophrenia for arts therapies, particularly for the alleviation of negative symptoms of the disorder. ${ }^{3}$

We examined the impact of adding group art therapy to the treatment of people with schizophrenia compared with both active control treatment and standard care alone on global functioning and symptoms of schizophrenia.

\section{Methods}

The MATISSE (Multicenter study of Art Therapy In Schizophrenia: Systematic Evaluation) study was a rater blinded, parallel group, randomised controlled trial of either group art therapy plus standard care, activity groups plus standard care, or standard care alone. ${ }^{9}$ We carried out a parallel economic evaluation (reported elsewhere) and a process evaluation, which examined the organisation and delivery of treatment in the study and the relation between treatment process and treatment outcomes.

\section{Participants}

Study participants were recruited from community based mental health and social care services in four centres in England and Northern Ireland. We also considered inpatients, but eligible participants were not randomised until after discharge from inpatient care. Participants were aged 18 years or over and had a clinical diagnosis of schizophrenia, confirmed by an examination of case notes using operationalised criteria. ${ }^{10}$ To take part in the study, potential participants had to be willing to take part in group therapy and to provide written informed consent. We excluded those with severe cognitive impairment, those who were unable to speak sufficient English to complete the baseline assessment, and those already receiving art or another creative therapy. Health and social care professionals working on inpatient units or in community teams, day centres, and rehabilitation and residential units identified potential participants. Researchers and clinical studies officers of the UK
Mental Health Research Network met those who had given verbal consent to be approached about the study, assessed eligibility, provided written and verbal information, and obtained written informed consent.

\section{Randomisation and masking}

Following completion of baseline assessments, participants were randomised through an independent and remote telephone randomisation service provided by the Aberdeen Clinical Trials Unit. We used permuted blocks, stratified by site. Block size was randomly assigned between three and six. Participants and clinical staff were aware of the trial arm to which the study participants were allocated but all interviews were done by researchers blinded to allocation status. Researchers were asked to guess what arm participants had been randomised to after the final follow-up interview had been completed.

\section{Interventions}

Those randomised to group art therapy were offered weekly sessions of 90 minutes' duration for an average of 12 months. Art therapy was carried out in keeping with recommendations of the British Association of Art Therapists ${ }^{11}$ and aimed to enhance self expression, improve emotional health, and help people develop better interpersonal functioning. Patients were given access to a range of art materials and encouraged to use these to express themselves freely. Art therapists generally adopted a supportive approach, offering empathy and encouragement. They rarely provided psychotherapeutic interpretations of interpersonal process or images. They did, however, frequently discuss these processes in supervision. Within this framework, therapists employed specific therapeutic interventions considered appropriate to individual needs and circumstances. This approach is in keeping with recommendations for the pragmatic evaluation of complex interventions in which individual therapists are encouraged to apply treatment principles flexibly to fit with the needs of participants. ${ }^{12}$

Activity groups also took place on a weekly basis and were made available to participants for an average of 12 months. Facilitators of these groups encouraged participants to agree activities collectively; these included playing board games, watching and discussing DVDs, and visiting local cafes. The use of art materials was prohibited. Group facilitators were asked to refrain from exploring the thoughts and feelings of study participants or offering psychotherapeutic interventions. All art therapy and activity groups were cofacilitated by a member of staff or volunteer who received training in the trial and intervention. During the treatment phase of the trial, art therapists and activity group facilitators received monthly group supervision from a senior practitioner with relevant expertise. Recordings of each supervision session were reviewed by a senior member of the study team who provided feedback to supervisors about adherence to agreed guidelines for the delivery of respective interventions. Standard care involved follow-up from secondary care mental health services, care coordination, pharmacotherapy, and the option of referral to other services as clinically indicated, except other creative therapies, which participants agreed not to undertake until completion of follow-up.

\section{Outcome measures}

The primary outcomes for the study were global functioning (measured using the global assessment of functioning scale) ${ }^{13}$ and symptoms of schizophrenia (measured using the positive 
and negative syndrome scale) assessed at 24 months. ${ }^{14}$ Secondary outcomes were global functioning and mental health symptoms measured at 12 months as well as levels of group attendance, social functioning (measured using the social function questionnaire) ${ }^{15}$ adherence with prescribed drugs (measured using the Morisky scale),${ }^{16}$ satisfaction with care (measured using the client satisfaction questionnaire), ${ }^{17}$ mental wellbeing (measured using the general wellbeing scale),${ }^{18}$ and health related quality of life (measured using the five item EQ-5D) ${ }^{19}$ assessed at 12 and 24 months after randomisation. ${ }^{20}$

\section{Statistical analysis}

The sample size was based on detecting a minimal clinically significant difference of 6 (SD 10) points on the global assessment of functioning scale at 24 months, between those randomised to art therapy and those randomised to active control or standard care alone. Taking into account an inflation factor for therapist clustering of 2.22 (based on eight participants or therapists and an intraclass correlation coefficient of 0.175 ) and a $20 \%$ loss to follow-up, we aimed to recruit 376 participants. All primary statistical analyses were done using the intention to treat principle. We imputed missing baseline data using regression or mean imputation. Follow-up data were not imputed. Differences in mean score between those randomised to each of the three trial arms were examined using analysis of covariance adjusting for baseline value of the outcome, site, sex, and age. All secondary outcomes (positive and negative syndrome scale and global assessment of functioning score at 12 months, and positive and negative syndrome scale; negative, positive, and general symptoms subscales; social function; wellbeing; drugs; and satisfaction with services at 12 and 24 months) were analysed in a similar way. We report any significant findings. To take into account the clustered structure of the data we fitted different mixed effects models as sensitivity analyses, including a two level heteroscedastic model allowing the within site variance to differ across arms, and a three level model, with study centre as level 3 and site as level $2 .{ }^{21}$

In another secondary analysis we examined the impact of the uptake of the interventions on our primary outcomes using two stage least squares estimates. ${ }^{22}$ This analysis is based on instrumental variable methods and avoids the selection bias of per protocol or as treated analysis. The approach assumes that the effect of allocation to treatment has no effect on the outcome if the patient does not receive the treatment. As there are no data to suggest that there is a minimum number of sessions of art therapy that someone needs to attend to derive benefit from this intervention, we used this approach to estimate the benefit per session, assuming it is proportional to the number of sessions attended, when adjusted for site, sex, and age. All $P$ values were two sided and considered significant when less than 0.05 .

\section{Results}

In total, 649 people were assessed for the study over a 19 month period between February 2007 and August 2008. Of these, 417 $(64 \%)$ were randomised, $361(87 \%)$ were followed up at 12 months, and $355(85 \%)$ were followed up at 24 months. The figure $\Downarrow$ presents the reasons for non-participation and attrition. Table $1 \Downarrow$ shows the baseline characteristics of the participants. Study participants had a mean age of 41 and a mean duration of illness of 17 years. All but $15(4 \%)$ were being prescribed antipsychotic drugs, and 134 (32\%) had had a period of inpatient psychiatric treatment in the 12 months before randomisation. The attrition rate was similar across arms, and reasons for attrition did not differ (death, withdrawal, lost to follow-up).
Of the seven deaths, four were from suicide or probable suicide. Three additional serious adverse events were reported, one a near fatal episode of deliberate self harm and two involving harm to others. None seemed to be related to the interventions being examined in the study.

Participants who completed follow-up had baseline characteristics similar to those who did not, but attrition rates varied by study centre. When researchers attempted to guess allocation status after the final follow-up interview, almost half of the guesses were correct $(n=119,48 \%)$.

Those allocated to art therapy attended between 0 and 51 groups, and those allocated to control groups attended between 0 and 45 groups. Eighty six $(61 \%)$ of those randomised to art therapy and $73(52 \%)$ randomised to activity control groups attended at least one group. Among those who attended one or more groups, median levels of attendance were higher among those randomised to group art therapy (11 for art therapy versus five for activity groups, $\mathrm{P}=0.04$ ). The median delay between randomisation and someone attending his or her first group was 61 days for both art therapy and activity groups. The content of audio recordings showed that supervision sessions of both art therapy and activity groups were delivered in a consistent manner across study centres.

Table $2 \Downarrow$ presents the baseline and follow-up outcome scores by trial arm. During the two year follow-up period, the number of total symptoms of schizophrenia decreased. No differences in primary outcomes were found between trial arms. The adjusted mean difference between those randomised to art therapy and those randomised to standard care alone on the global assessment of functioning scale was -0.9 (95\% confidence interval -3.8 to $2.1, \mathrm{P}=0.57)$ and on the positive and negative syndrome scale was 0.7 ( -3.1 to $4.6, \mathrm{P}=0.71)$. The adjusted mean difference between those randomised to art therapy and those randomised to activity groups on the global assessment of functioning scale was $-1.1(-4.0$ to $1.8, \mathrm{P}=0.47)$ and on the positive and negative syndrome scale was $3.1(-0.7$ to $6.9, \mathrm{P}=0.11$ ). Global assessment of functioning scores at 24 months showed little clustering across study sites (intraclass correlation coefficient 0.06 ), but variance between sites in scores on the positive and negative syndrome scale was important (intraclass correlation coefficient 0.47 ). None of the mixed models that were fitted to take into account the clustered structure of the data showed significant differences in the primary outcome between groups.

Wellbeing, satisfaction with care, or other secondary outcomes at 12 and 24 months did not differ significantly, except that those referred to an activity group had fewer positive symptoms of schizophrenia at 12 and 24 months compared with those randomised to group art therapy (adjusted mean difference 1.4, $95 \%$ confidence interval 0.1 to $2.6, \mathrm{P}=0.03$ ).

Analysis of instrumental variables indicated that attendance at art therapy groups was not associated with improvements in global functioning or in symptoms of schizophrenia (table $3 \Downarrow$ ).

\section{Discussion}

In this randomised trial the mental health and global functioning of people with schizophrenia was not improved by offering a place in a weekly art therapy group in addition to their standard care. Those randomised to weekly group art therapy had similar levels of global functioning and mental health as those randomised to an activity control group over a two year period, except that the activity control group had a greater reduction in positive symptoms of schizophrenia at 24 months. People offered a place in an art therapy group were more likely to attend 
sessions than those offered a place in an activity group, but levels of attendance at both types of group were low.

\section{Strengths and weaknesses of the study}

The main strengths of the study are that it was adequately powered, used a rigorous approach to minimising bias, and used broad inclusion criteria to assess whether the intervention could help most people with schizophrenia. Data from a national survey of art therapists working throughout England and carried out in parallel with this trial suggested that the approach used to deliver art therapy in the study is the same as that used more widely across the country. ${ }^{23}$ The study was not, however, without its limitations, chief among these being the level of engagement with the intervention. We deliberately set out to test the effectiveness of group art therapy among most people with schizophrenia who expressed a willingness to use this form of treatment. Almost $40 \%$ of participants randomised to group art therapy did not attend any sessions. Among those who did, few attended regularly. Possible explanations for the low level of attendance are that the interventions may not have been acceptable to participants or that participants lacked the motivation and organisational skills to attend. ${ }^{24}$ However, the average effect of attendance at art therapy among the compliant population was estimated in a two stage least squares estimation, which suggested that even in those willing to participate in art therapy, attendance was not related to study outcomes.

Many groups had only one or two regular attendees, with an average of two or three people attending art therapy groups. Although this meant that therapists may have been able to pay greater attention to each participant than would have been possible in a larger group, opportunities for group members to interact with each other were more limited. ${ }^{25}$

We did not collect outcome data during the intervention phase of the study, potentially precluding observation of short term benefits. However, the absence of statistically or clinically significant differences in outcomes between participants in the three intervention arms at 12 months suggests that even if short term benefits did occur, these dissipated within a year. Previous accounts of the potential benefits of group art therapy suggest that it may help people in ways that are difficult to quantify. ${ }^{25}$ We do not know whether art therapy resulted in other outcomes that are valued by service users but were not measured in this trial. Nevertheless, our study did not corroborate the findings of other small smaller scale trials of creative therapies that have shown improvements in symptoms of schizophrenia. ${ }^{26}$

\section{Comparison with other studies}

Levels of attendance at group art therapy were also low in the two previous community based randomised trials of group art therapy. In the first ever clinical trial of art therapy, the researchers studied 47 people with chronic mental illness of whom half had a diagnosis of schizophrenia. ${ }^{27}$ Detailed information about levels of attendance were not provided but the authors state that among 19 people who were followed up, eight (42\%) attended fewer than three sessions of art therapy. The authors compared outcomes between patients who completed 10 groups with those who did not and found that the completers had higher levels of self esteem.

In a subsequent trial, the researchers examined the effects of adding up to 12 sessions of weekly group art therapy to the standard care of people with schizophrenia. ${ }^{8}$ Among those offered a place in an art therapy group, mean attendance was 3.5 sessions, and $37 \%$ attended no sessions at all. Fewer than half of all participants were followed up at six months, but among those who were followed up a statistically significant reduction in negative symptoms was found. It is unclear whether the researchers who carried out follow-up assessments in these trials were masked to the allocation status of participants.

\section{Conclusions and future research}

These findings challenge current national treatment guidelines that clinicians should consider referring all people with schizophrenia for arts therapies. ${ }^{3}$ Although we cannot rule out the possibility that group art therapy benefits people with schizophrenia who are motivated to use this treatment, our findings suggest that it does not lead to improved patient outcomes when offered to most people with this disorder.

Levels of attendance at art therapy may be higher when people are receiving inpatient treatment, ${ }^{28}$ and the impact of art therapy delivered in this setting should be studied.

Results of randomised trials of other creative therapies for people with schizophrenia, such as music therapy and body movement therapy, are more promising. ${ }^{29} 30$ These interventions combine creativity with other approaches specifically aimed at providing an enjoyable experience, stimulating physical movement, and increasing interactions with others. Although it has been argued that involvement in creative activities is inherently good for mental health, it may be that for people with severe mental illnesses such as schizophrenia it is only when such activities are used in combination with other interventions that benefits are seen.

We thank Sakina Hossany, Aimee Ayton, and Martin Keats for helping to coordinate the study and enter and manage study data; the Mental Health Research Network for supporting the recruitment and follow-up of participants; and patients and staff who took part in the study. A more detailed account of the study methods and findings will be published in full in Health Technology Assessment in 2012.

Contributors: MJC, HK, and DW are coprincipal investigators of the MATISSE trial, had full access to all of the data in the study, and take responsibility for the integrity of the data and the accuracy of the data analysis. EK designed the statistical analysis plan with guidance provided by TJ. Outcome data were analysed by BL with guidance from TJ. DW, $\mathrm{KC}$, and $\mathrm{AM}$ provided clinical expertise on arts therapies. DPO led the training of activity group facilitators. The principal investigators at each centre were MJC, HK, TS, and FAO'N. SP, AH, SF, and JD recruited and followed up participants. MK, BB, SB, TREB, and PT provided expertise in trial methods, including input to the planning of the study and the data analysis plan. All study authors contributed to the preparation of this report. MJC is the guarantor.

Funding: The project was funded by the National Institute for Health Research Health Technology Assessment programme (project No 04/39/04) and received financial support from Avon and Wiltshire Mental Health Partnership NHS Trust, Belfast Health and Social Care Trust, Camden and Islington NHS Foundation Trust, and Central and North West London NHS Foundation Trust. The sponsors of the study played no part in the preparation of this paper. The views and opinions expressed therein are those of the authors and do not necessarily reflect those of the Health Technology Assessment programme, the National Institute for Health Research, or the Department of Health.

Competing interests: All authors have completed the ICMJE uniform disclosure form at www.icmje.org/coi_disclosure.pdf (available on request from the corresponding author) and declare: no support from any organisation for the submitted work; no financial relationships with any organisations that might have an interest in the submitted work in the previous three years; DW, AM, and MJC are executive members of a non-profit organisation (the International Centre for Research in 


\section{What is already known on this topic}

Although drugs can reduce the symptoms of schizophrenia, many people still experience poor mental health and social functioning Group art therapy has been used as adjunctive treatment for people with schizophrenia, but few studies have examined its clinical effects

\section{What this study adds}

Group art therapy, as delivered in this trial, did not improve global functioning or health outcomes of people with schizophrenia Levels of attendance at both art therapy and activity groups were low Although group art therapy may benefit a few highly motivated people, evidence of improved patient outcomes for most people with schizophrenia was lacking

Arts Therapies) that aims to promote research and development of arts therapies in health and social care.

Ethical approval: This study was approved by the Huntingdon research ethics committee (06/Q0104/82).

Data sharing: No additional data available.

1 Andreasen NC, Olsen S. Negative v positive schizophrenia. Definition and validation. Arch Gen Psychiatry 1982;39:789-94.

2 Robinson D, Woerner MG, Alvir JM, Bilder R, Goldman R, Geisler S, et al. Predictors of relapse following response from a first episode of schizophrenia or schizoaffective disorder. Arch Gen Psychiatry 1999;56:241-7.

3 National Institute for Health and Clinical Excellence. NICE clinical guideline 82. Schizophrenia: core interventions in the treatment and management of schizophrenia in adults in primary and secondary care. NICE, 2009.

4 Pfammatter M, Junghan UM, Brenner HD. Efficacy of psychological therapy in schizophrenia: conclusions from meta-analyses. Schizophr Bull 2006;32:S64-80.

5 Spencer D. The art of noise. BMJ 2010;341:c6038.

6 Killick K. Unintegration and containment in acute psychosis. Art, psychotherapy and psychosis. Routledge, 1997.

7 Ruddy R, Milnes D. Art therapy for schizophrenia or schizophrenia-like illnesses. Cochrane Database Syst Rev 2005;4:CD003728.

8 Richardson P, Jones K, Evans C, Stevens P, Rowe A. Exploratory RCT of art therapy as an adjunctive treatment in schizophrenia. $J$ Mental Health 2007;16:483-91.

9 Crawford MJ, Killaspy H, Kalaitzaki E, Barrett B, Byford S, Patterson S, et al. The MATISSE study: a randomised trial of group art therapy for people with schizophrenia. BMC Psychiatry 2010;10:65.

10 McGuffin P, Farmer A, Harvey I. A polydiagnostic application of operational criteria in studies of psychotic illness. Development and reliability of the OPCRIT system. Arch Gen Psychiatry 1991;48:764-70.

11 British Association of Art Therapists. What is art therapy? www.baat.org/art_therapy.html. 2011.

12 Thorpe KE, Zwarenstein M, Oxman AD, Treweek S, Furberg CD, Altman DG, et al. A pragmatic-explanatory continuum indicator summary (PRECIS): a tool to help trial designers. J Clin Epidemiol 2009:62:464-75.

13 Jones SH, Thornicroft G, Coffey M, Dunn G. A brief mental health outcome scale-reliability and validity of the Global Assessment of Functioning (GAF). Br J Psychiatry 1995;166:654-9.

14 Kay SR, Fiszbein A, Opler LA. The positive and negative syndrome scale (PANSS) for schizophrenia. Schizophr Bull 1987;13:261-76.

15 Tyrer P, Nur U, Crawford M, Karlsen S, McLean C, Rao B, et al. The Social Functioning Questionnaire: a rapid and robust measure of perceived functioning. Int $J$ Soc Psychiatry 2005;51:265-75
16 George CF, Peveler RC, Heiliger S, Thompson C. Compliance with tricyclic antidepressants: the value of four different methods of assessment. Br J Clin Pharmacol 2000;50:166-71.

17 Atkinson C, Greenfield T. Client Satisfaction Questionnaire-8 and Service Satisfaction Scale 30. In: Atkinson C, Greenfield T, eds. Psychological testing: treatment planning and outcome assessment. Lawrence Erlbaum Associates 1994:404-20.

18 Norman RM, Malla AK, McLean T, Voruganti LP, Cortese L, McIntosh E, et al. The relationship of symptoms and level of functioning in schizophrenia to general wellbeing and the Quality of Life Scale. Acta Psych Scand 2000;102:303-9.

19 Brooks R. EuroQol: the current state of play. Health Policy 1995;37:53-72.

20 Kuyken W, Byford S, Taylor RS, Watkins E, Holden E, White K, et al. Mindfulness-based cognitive therapy to prevent relapse in recurrent depression. $J$ Consult Clin Psychol 2008;76:966-78.

21 Walwyn R, Roberts C. Therapist variation within randomised trials of psychotherapy: implications for precision, internal and external validity. Stat Methods Med Res 2010;19:291-315.

22 Angrist JD, Imbens GW. Two-stage least squares estimation of average causal effects in models with variable treatment intensity. J Am Stat Assoc 1995;90:431-42.

23 Patterson S, Debate J, Anju S, Waller D, Crawford MJ. Provision and practice of art therapy for people with schizophrenia: results of a national survey. $J$ Ment Health 2011;20:328-35.

24 Killaspy H, Banerjee S, King M, Lloyd M. Prospective controlled study of psychiatric out-patient non-attendance. Characteristics and outcome. Br J Psychiatry 2000;176:160-5.

25 Waller D. Group interactive art therapy: its use in training and treatment. Routledge, 1996.

26 Crawford MJ, Patterson S. Arts therapies for people with schizophrenia: an emerging evidence base. Evid Based Ment Health 2007;10:69-70.

27 Green BL, Wehling C, Talsky GJ. Group art therapy as an adjunct to treatment for chronic outpatients. Hosp Community Psychiatry 1987;38:988-91.

28 Meng P, Zheng R, Cai Z, Cao Dahong, Ma L, Liu J, et al. Group intervention for schizophrenia inpatient with art as medium. Acta Psych Sinica 2005;37:403-12. [ln Chinese.]

29 Talwar N, Crawford MJ, Maratos A, Nur U, McDermott O, Procter S. Music therapy for in-patients with schizophrenia: exploratory randomised controlled trial. Br J Psychiatry 2006; 189:405-9.

30 Rohricht $F$, Priebe $S$. Effect of body-oriented psychological therapy on negative symptoms in schizophrenia: a randomized controlled trial. Psychol Med 2006;36:669-78.

Accepted: 7 December 2011

\section{Cite this as: BMJ 2012:344:e846}

This is an open-access article distributed under the terms of the Creative Commons Attribution Non-commercial License, which permits use, distribution, and reproduction in any medium, provided the original work is properly cited, the use is non commercial and is otherwise in compliance with the license. See: http://creativecommons.org/licenses/bync/2.0/ and http://creativecommons.org/licenses/by-nc/2.0/legalcode. 


\section{Tables}

Table $1 \mid$ Personal characteristics of participants at baseline. Values are numbers (percentages) unless stated otherwise

\begin{tabular}{|c|c|c|c|c|}
\hline Variable & Standard care $(n=137)$ & Activity group ( $n=140$ ) & Art therapy $(n=140)$ & Total $(n=417)$ \\
\hline Mean (SD) age (years) & $40(12)$ & $42(12)$ & $41(11)$ & $41(12)$ \\
\hline Men & $99(72)$ & $90(64)$ & $90(64)$ & $279(67)$ \\
\hline Women & $38(28)$ & $50(36)$ & $50(36)$ & $138(33)$ \\
\hline \multicolumn{5}{|l|}{ Marital status: } \\
\hline Married or cohabiting & $8(6)$ & $12(9)$ & $11(8)$ & $31(7)$ \\
\hline Divorced or separated & $9(7)$ & $21(15)$ & $17(12)$ & $47(11)$ \\
\hline Widowed & $3(2)$ & $1(1)$ & $1(1)$ & $5(1)$ \\
\hline Single & $117(85)$ & $106(76)$ & $111(79)$ & $334(80)$ \\
\hline \multicolumn{5}{|l|}{ Education*: } \\
\hline Degree & $18(14)$ & $15(11)$ & $12(9)$ & $45(11)$ \\
\hline Other & $54(42)$ & $64(46)$ & $59(43)$ & $177(44)$ \\
\hline Vocational training & $22(17)$ & $13(9)$ & $18(13)$ & $53(13)$ \\
\hline None & $35(27)$ & $46(33)$ & $48(35)$ & $129(32)$ \\
\hline
\end{tabular}

*Data on 404 participants. 


\begin{tabular}{|c|c|c|c|c|c|c|c|c|c|}
\hline \multirow[b]{2}{*}{ Outcome measure $^{*}$} & \multicolumn{3}{|c|}{ Standard care } & \multicolumn{3}{|c|}{ Activity groups } & \multicolumn{3}{|c|}{ Group art therapy } \\
\hline & $\begin{array}{l}\text { Baseline } \\
(n=137)\end{array}$ & $\begin{array}{c}12 \text { months } \\
(n=121)\end{array}$ & $\begin{array}{c}24 \text { months } \\
(n=117)\end{array}$ & $\begin{array}{l}\text { Baseline } \\
(n=140)\end{array}$ & $\begin{array}{c}12 \text { months } \\
(n=121)\end{array}$ & $\begin{array}{l}24 \text { months } \\
(n=121)\end{array}$ & $\begin{array}{l}\text { Baseline } \\
(n=140)\end{array}$ & $\begin{array}{c}12 \text { months } \\
(n=119)\end{array}$ & $\begin{array}{c}24 \text { months } \\
(n=117)\end{array}$ \\
\hline \multicolumn{10}{|l|}{ Primary outcomes: } \\
\hline $\begin{array}{l}\text { Global assessment } \\
\text { of functioning }(n=355)\end{array}$ & $44.9(12.6)$ & $45.7(14.4)$ & $46.8(12.8)$ & $45.0(12.7)$ & $45.5(14.1)$ & $46.4(13.6)$ & $44.8(13.1)$ & $44.9(14.6)$ & $45.6(13.1)$ \\
\hline $\begin{array}{l}\text { Positive and negative } \\
\text { syndrome scale total } \\
\text { score }(n=348)\end{array}$ & $72.6(21.5)$ & $71.2(24.6)$ & $68.1(20.7)$ & $75.3(22.0)$ & $69.6(23.2)$ & $66.9(23.3)$ & $74.3(23.7)$ & 72.7 (27.3) & $69.2(21.8)$ \\
\hline \multicolumn{10}{|l|}{ Secondary outcomes: } \\
\hline $\begin{array}{l}\text { Positive symptoms } \\
\text { score }(n=348)\end{array}$ & $17.3(5.6)$ & $16.7(6.3)$ & $16.1(5.5)$ & $18.2(6.8)$ & $16.1(5.9)$ & $15.6(6.4)$ & $18.0(6.9)$ & $17.3(7.6)$ & $16.8(6.5)$ \\
\hline $\begin{array}{l}\text { Negative symptoms } \\
\text { score }(n=348)\end{array}$ & $18.5(7.5)$ & $18.2(7.7)$ & $17.2(7.3)$ & $18.7(7.0)$ & $17.3(7.2)$ & $16.4(6.8)$ & $18.7(7.1)$ & $18.4(8.0)$ & $16.9(7.1)$ \\
\hline $\begin{array}{l}\text { General symptoms } \\
\text { score }(n=348)\end{array}$ & $36.8(11.3)$ & $36.3(13.0)$ & $34.9(11.3)$ & $37.6(12.5)$ & $35.9(12.7)$ & $34.9(12.4)$ & $37.6(12.5)$ & $37.0(14.0)$ & $35.3(11.4)$ \\
\hline $\begin{array}{l}\text { Social functioning } \\
(\mathrm{n}=348)\end{array}$ & $8.1(4.7)$ & $8.5(4.9)$ & $8.1(4.8)$ & $9.0(4.8)$ & $8.1(4.6)$ & $8.0(4.5)$ & $8.6(4.2)$ & $8.3(5.0)$ & $8.2(4.8)$ \\
\hline Wellbeing $(n=348)$ & $64.5(20.6)$ & $64.1(23.7)$ & $68.1(18.8)$ & $59.1(19.5)$ & $63.6(23.2)$ & $66.1(18.4)$ & $58.3(21.1)$ & $59.6(20.8)$ & $65.1(18.6)$ \\
\hline $\begin{array}{l}\text { Satisfaction with care } \\
(\mathrm{n}=329)\end{array}$ & $24.9(5.7)$ & $24.3(6.4)$ & $24.2(5.3)$ & $23.8(6.2)$ & $25.0(5.2)$ & $24.9(5.0)$ & $24.8(5.7)$ & $23.6(6.5)$ & $23.1(5.9)$ \\
\hline $\begin{array}{l}\text { Morisky score } † \\
(\mathrm{n}=333)\end{array}$ & $1.2(1.3)$ & $0.7(1.1)$ & $0.6(0.9)$ & $1.2(1.3)$ & $0.6(0.9)$ & $0.5(0.9)$ & $1.0(1.2)$ & $0.7(1.0)$ & $0.6(0.9)$ \\
\hline
\end{tabular}


Table 3| Instrumental variables analysis at 24 month follow-up, adjusted for site, sex, and age

\section{Variables}

Coefficient $(95 \% \mathrm{Cl}) \mathrm{P}$ value

Global assessment of functioning ( $n=355)$ :

\begin{tabular}{lll}
\hline Group art therapy versus standard care & $-0.08(-0.35$ to 0.19$)$ & 0.55 \\
\hline Group art therapy versus activity group & $0.02(-0.38$ to 0.43$)$ & 0.91 \\
\hline Positive and negative syndrome scale $(\mathrm{n}=340):$ & & \\
\hline Group art therapy versus standard care & $0.07(-0.28$ to 0.42$)$ & 0.69 \\
\hline Group art therapy versus activity group & $-0.31(-0.84$ to 0.21$)$ & 0.24 \\
\hline
\end{tabular}




\section{Figure}

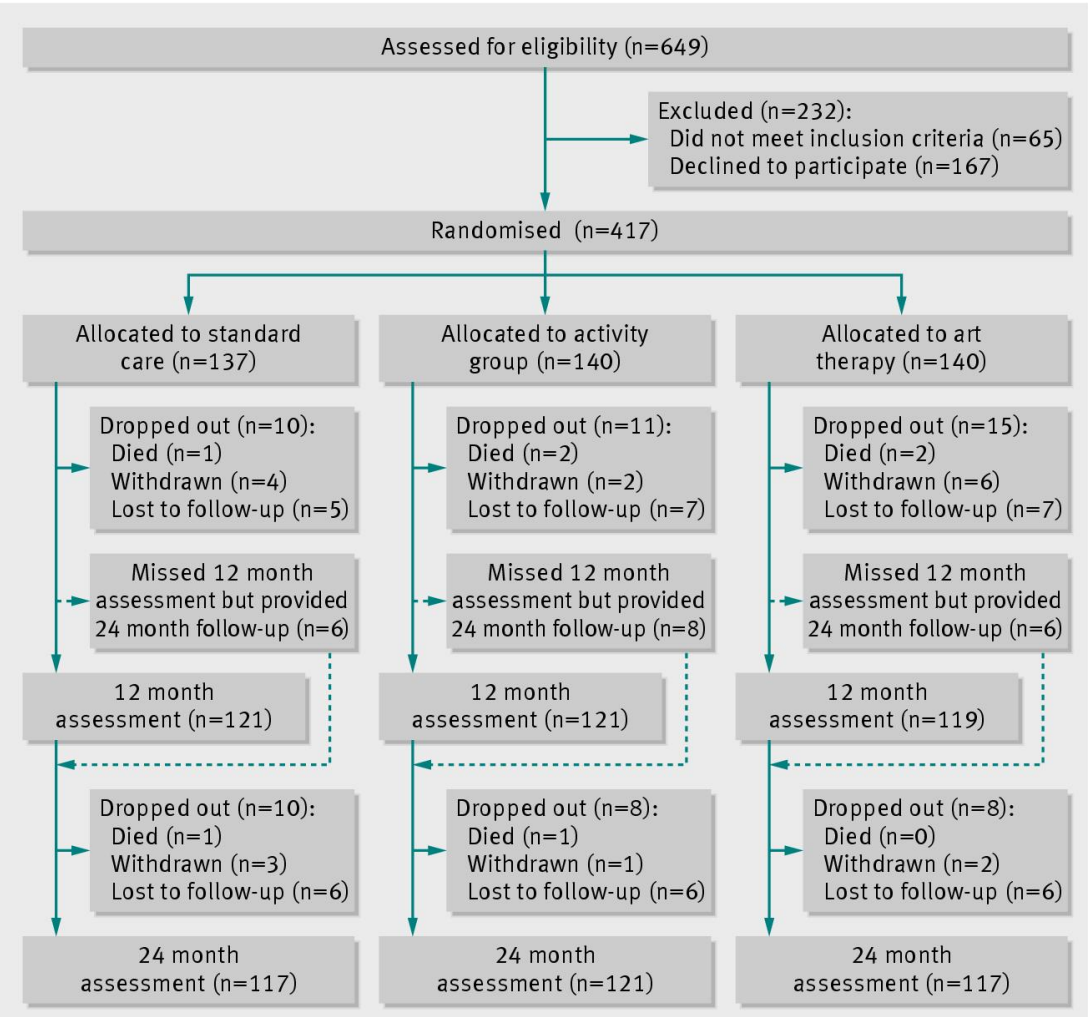

Flow of participants through study 